\title{
Happy, Healthy, Ready - working with early childhood non-government organisations for developmental surveillance for vulnerable children
}

\section{AUTHORS}

KAREN EDWARDS BA, Grad Dip Cont Ed, MBA ${ }^{1}$

RITIN FERNANDEZ PhD ${ }^{2}$

TANIA RIMES BSocSc(Psych), MA(Psych), GradDipPsychPrac(Org. Psych) ${ }^{3}$

LISA STEPHENSON BSocWork ${ }^{4}$

REBECCA SMITH BN, BSc, Grad Dip. Midwifery, Grad Cert. C\&FH Nursing ${ }^{5}$

JANE SON MBBS, DipPaed, FRACP, MIPH ${ }^{6}$

VANESSA SARKOZY MHM, MPH, FRACP, MRCPCH, $\mathrm{MBChB}, \mathrm{MPH}, \mathrm{MHM}^{7}$

DEBORAH PERKINS MBBS, BSc, DipPaed, $\mathrm{MPH}^{7}$

VALSAMMA EAPEN MBBS, PhD, FRCPsych, FRANZCP7,8

SUE WOOLFENDEN MBBS, FRACP, MPH, PhD7,9
1 Counterpoint Consulting Pty Ltd, Glen Innes, NSW, Australia

2 School of Nursing and Midwifery, Faculty of Science, Medicine and Health, University of Wollongong, NSW Australia

3 South Eastern Sydney LHD, Sydney, NSW, Australia

4 South Eastern Sydney LHD, Caringbah, NSW, Australia

5 Child and Family Health Nursing, South Eastern Sydney LHD, Ramsgate, NSW, Australia

6 Kogarah Developmental Assessment Service, South Eastern Sydney LHD, Kogarah, NSW, Australia

7 Sydney Children's Hospital, Randwick, NSW, Australia

8 School of Women and Children's Health, University of New South Wales; South West Sydney (AUCS); Early Life Determinants of Health, Sydney Partnership for Health, Education, Research and Enterprise (SPHERE); Cooperative Research Centre for Autism (CRC); BestSTART-SW (Systems Transformation and Research Translation - South West Sydney) Academic Unit; ICAMHS, L1 MHC, Liverpool Hospital, Liverpool, NSW, Australia

9 Integrated Care and Department of Community Child Health, Sydney Children's Hospitals Network; School of Public Health, the Faculty of Medicine and Health, University of Sydney, NSW, Australia

\section{CORRESPONDING AUTHOR}

KAREN EDWARDS Counterpoint Consulting Pty Ltd, PO Box 675, Glen Innes NSW 2370 Australia. Phone: +61 0401863 805. Email: karen@counterpointconsulting.com.au

\section{ABSTRACT}

Objective: This study sought to improve: (1) knowledge of child development among non-health child and family workers; and (2) identification and referral of children from culturally and linguistically diverse (CALD) backgrounds at developmental risk, by partnering child health services with nongovernment early childhood education and family support services in two suburbs with high numbers of families from CALD backgrounds.
Background: Children from CALD backgrounds have increased risk of developmental problems going undetected prior to school entry, thereby missing early intervention.

Study design and methods: This was a quality improvement project. The model comprised: (1) co-locating a child and family health nurse CAFHN in a non-health setting or visits by early 
childhood health staff to undertake developmental surveillance and (2) training non-health staff on child development and New South Wales (NSW) developmental surveillance tools. Evaluation used a mixed methods design analysing qualitative data from parents, early childhood workers, CAFHNs, and paediatricians and de-identified activity data from CAFHNs, and other early childhood health services.

Results: Non-health workers increased their referrals of children at developmental risk to CAFHN or other child health providers. In Rockdale, 44\% ( $n=62)$ and Botany $41 \%(n=98)$ of children screened had one or more significant developmental vulnerabilities. CAFHN reported developmental surveillance for families who were not accessing traditional clinicbased services.

Discussion: This study tested a model of developmental surveillance and entry into the child and family health system in a non-health setting, thus providing a 'soft' entry for parents who might not otherwise engage with these services.

Conclusion: The project demonstrated a new way of working for CAFHNs and facilitated identification of developmental risk in children from CALD backgrounds, who would otherwise have been missed.

Implications for research, policy, and practice: This relatively small-scale model of practice change has resulted in improved access for a marginalised population, but further research is needed to refine the model and test it for scalability and replicability.
What is already known about this topic?

Our team undertook a systematic review of outreach developmental surveillance occurring in non-health settings. Eight studies across high, middle and low income countries have been identified with a total of 150,047 children aged 18 months to five years, the majority from low socioeconomic backgrounds. Only one study has been based in Australia ${ }^{10}$ in a regional area in Victoria which showed increased detection of children who were developmentally vulnerable. No studies have had a specific focus on CALD populations in Australia or have been based in the context of the NSW health and developmental surveillance system.

\section{What this paper adds:}

This paper describes the outcomes of a quality improvement project implemented in Rockdale and Botany - two disadvantaged areas of South Eastern Sydney - to increase access to developmental surveillance and early intervention for children from culturally and linguistically diverse (CALD) backgrounds attending supported playgroups and early childhood education services.

Key words: Developmental screening, detection, child development, Child and Family Health Nurse (CAFHN), culturally and linguistically diverse (CALD), migrant, refugee, interagency, multi-agency

\section{INTRODUCTION}

One in five Australian children starting school are developmentally vulnerable, which means that they do not have the skills (learning, socio-emotional, physical) to flourish at school. ${ }^{1}$ Developmentally vulnerable children are at increased risk of poor long term adverse academic, health and vocational outcomes..$^{2-5}$

Children from non-English speaking homes, who are not proficient in English at school entry and/or socioeconomically disadvantaged, are 1.5 times more likely to be developmentally vulnerable compared to their English speaking and/or more affluent peers. ${ }^{3,6}$ Given the potentially adverse long-term consequences of developmental vulnerability, children who are developmentally vulnerable need to be identified as early as possible so that they can be referred for early intervention and receive support prior to school commencement. $5,7,8$
Unfortunately, only $18 \%$ of children who are developmentally vulnerable receive early intervention in the preschool years. ${ }^{1}$ This is despite the fact that in New South Wales (NSW) there is a program of universal early childhood developmental surveillance throughout the early years, starting at birth (the zero to four weeks check) and continuing to age four, prior to enrolment in school. Traditionally the model of early childhood developmental surveillance through NSW public health services is through a single universally offered home visit in the first few weeks after a baby's birth (the o - four week check) by a child and family health nurse (CAFHN), with parents then invited to visit local child and family health centres for the remaining checks, also undertaken by a CAFHN. Child and family health nurses provide a universal 'soft' entry point into the health system supporting access to early intervention. Generally speaking, CAFHNs work in child and family health centres in a centre-based setting, other than when undertaking the universal home visit. 
Centre-based CAFHN services are universally available but may be harder to access for vulnerable families. Research in disadvantaged areas of Sydney found that socioeconomically disadvantaged families from CALD backgrounds were not attending child and family health centres and were therefore missing developmental checks. ${ }^{4}$

Services should consider how they invest their resources to specifically target those families whose cultural, locational or economic context create social determinants that adversely affect their long-term health outcomes.

There has been increasing interest in models of early childhood developmental surveillance that address poor access to mainstream services and subsequent long-term disadvantage for vulnerable families, including those from CALD backgrounds. ${ }^{9}$

These sites were chosen due to documented disparities in the performance of children from Rockdale and Botany on the Australian Early Development Census (AEDC) compared to the NSW average. For Rockdale and Botany, the proportions of children identified in the AEDC as developmentally vulnerable on one or more domains were $22.2 \%$ and $23.1 \%$ respectively, compared to $20.2 \%$ NSW average. In addition, child and family healthcare providers, including CAFHNs, and staff in non-government organisation (NGO) early childhood services were noting under-representation of CALD families in early childhood developmental surveillance. Children might be referred to a supported playgroup because of familial vulnerabilities but this does not automatically equate to a referral to a CAFHN or other providers of early childhood developmental surveillance. As a response, a model of practice for CAFHNs in a non-health setting was designed and tested, the elements of which, if successful, might be replicated or adapted in other locations.

Our objectives were to:

(1) Investigate the effect of a training program on the knowledge levels relating to child development among non-health child and family workers.

(2) Identify if there had been an improvement in identification and referral of children at developmental risk from CALD background when the model was implemented.

(3) Ascertain the views of service providers, parents or grandparent caregivers on the suitability of the model for the participating families.

In Rockdale, CAFHNs were fundamental to the study and testing of the non-health setting model of practice.

\section{METHODS}

\section{MODEL}

The model comprised: (1) co-locating a CAFHN or regular visits by early childhood health staff (community child health doctor, paediatrician, speech pathologist) to undertake early childhood developmental surveillance in NGO providing early childhood services, supported playgroups or family support services; and (2) training NGO early childhood staff on child development and use of the Parents' Evaluation of Developmental Status (PEDS), which was the NSW Health developmental surveillance tool at the time. This tool has now been replaced by the "Learn the Signs - Act Early" parental self-assessment tool.

The PEDS is an evidence-based screening tool in the form of a 10-item questionnaire that elicits and addresses parental concerns about children's development, health and wellbeing. It is completed by the parent individually or in consultation with their healthcare provider, usually a CAFHN. This tool was used by NGO early childhood staff in discussion with parents. Early childhood health providers score the PEDS form to identify concerns that predict issues if identified at particular points in a child's development (predictive or non-predictive concerns). The PEDS Interpretation Form assists early childhood healthcare providers, such as CAFHNs, to make the decision to refer, further screen, keep a watch, advise parents or reassure.

Parents identified by NGO early childhood service staff as having concerns (via PEDS) or identified as having not attended scheduled early childhood health checks were referred for a developmental screen with a CAFHN or community child health doctor. Staff in the participating supported play group and family worker program described 'warm transfers' where they walked a parent in to the CAFHN for an appointment.

If required, children were referred by the CAFHN for further specialist assessment to a Developmental Assessment Service. The team from the Developmental Assessment Service visited the site as well and this was identified as an enabler for some families to take the step to additional assessment and support.

The Botany project entailed visits to supported playgroups from Community Child Health Doctor and Speech Pathologist, with some assessments conducted in local and familiar locations (e.g. shopping centre). A CAFHN became part of the team during the study and visited playgroups to meet parents and discuss child development.

\section{EVALUATION DESIGN}

A mixed-methods design was used to evaluate this quality improvement project. The qualitative study included focus groups, interviews with service providers, parents, and grandparent caregivers to understand the suitability 
of the model components for participating families. The quantitative study entailed a retrospective review of the Community Health and Outpatient Care (CHOC) activity database for the Rockdale and Botany areas and descriptive analysis of the data.

\section{DATA COLLECTION}

In Rockdale, $45 \%$ of children lived in a home where English was not the language spoken at home. After English, Nepali was the most frequently spoken language at home, followed by Mandarin and Cantonese.

The table below describes the data sources and data collection methods:

\section{TABLE 1: DATA SOURCE AND COLLECTION METHOD}

\begin{tabular}{|c|c|c|}
\hline Data source & $\mathrm{n}$ & $\begin{array}{l}\text { Data collection } \\
\text { method }\end{array}$ \\
\hline $\begin{array}{l}2 \times \text { English-speaking parent/ } \\
\text { grandparent focus groups } \\
\text { with mixed participants from } \\
\text { different ethnic backgrounds. } \\
1 \times \text { Nepali speaking parent/ } \\
\text { grandparent focus group } \\
1 \times \text { Bengali speaking parent/ } \\
\text { grandparent focus group }\end{array}$ & $\begin{array}{l}\mathrm{n}=30 \\
(\text { approx.)* }\end{array}$ & $\begin{array}{l}\text { Collected during NGO } \\
\text { supported playgroups } \\
\text { in Botany and Rockdale } \\
\text { attended by parents } \\
\text { and/or grandparents } \\
\text { with their children/ } \\
\text { grandchildren }\end{array}$ \\
\hline $\begin{array}{l}\text { Interviews with NGO and } \\
\text { health providers in Botany } \\
\text { and Rockdale. }\end{array}$ & $n=13$ & $\begin{array}{l}\text { Collected in the } \\
\text { participant's workplace } \\
\text { or by telephone }\end{array}$ \\
\hline $\begin{array}{l}\text { Results from pre and post } \\
\text { training survey of } \mathrm{NGO} \\
\text { attendees to assess changes } \\
\text { in knowledge as a result of } \\
\text { the training. }\end{array}$ & $n=16$ & $\begin{array}{l}\text { Provided by survey } \\
\text { author }\end{array}$ \\
\hline $\begin{array}{l}\text { Results from previously } \\
\text { administered parent survey } \\
\text { in Rockdale (English speaking } \\
\text { only) }\end{array}$ & $\mathrm{n}=<50$ & $\begin{array}{l}\text { Provided by survey } \\
\text { author }\end{array}$ \\
\hline $\begin{array}{l}\text { Activity data collected by } \\
\text { Sydney Children's Hospital } \\
\text { (SCH) and South Eastern } \\
\text { Sydney Local Health District } \\
\text { (SESLHD) }\end{array}$ & $n=149$ & $\begin{array}{l}\text { Provided by } \mathrm{SCH} \text { and } \\
\text { SESLHD }\end{array}$ \\
\hline
\end{tabular}

\section{QUANTITATIVE DATA COLLECTION}

Knowledge: Pre and post-training surveys were administered to attendees to assess changes in knowledge as a result of the training. A total of 22 staff attended the training, with 21 (95\%) completing the pre-training survey and 16 (76\%) completing the post-training survey. The survey was completed by attendees prior to completion of the training and readministered two months post-training by the project officer (LS) and project lead (SW).

Retrospective audit: The de-identified data collected by the project officer (LS) or project leads (VS; DP; JS; SW) covered the period from commencement of the model in 2014 up to June 2018 and included age of child, country of birth, language spoken at home, and country of birth of parents (if collected) as well as developmental vulnerabilities identified and service contacts with CAFHN.

\section{QUALITATIVE DATA COLLECTION METHODS}

Focus groups: Parents and grandparents were invited by participating NGO services to take part in focus groups to gather their views of the model and their perception of how it has affected them and their families. English speaking focus groups were moderated by the English-speaking research assistant (KE). Two language groups were planned to be homogenous to enable culturally specific discussion. One of these groups was moderated by a Nepali-speaking facilitator, and the other by a Bengali-speaking facilitator using the interview guide in Figure 1. Both facilitators were trained in group facilitation, were briefed by the research assistant (KE) prior to the focus groups and debriefed afterwards by KE. English-speaking focus groups were audio recorded and transcribed verbatim using a transcription service.

Parent/Grandparent Focus Group Guide

1 What does child development mean to you?

2 How has your understanding of child development changed since you first started coming to (playgroup, childcare, family support, CAFHN clinic)?

3 What do you think helps or hinders a child's ability to develop? Why do you say this?

4 How do you get information if you have questions about your child's development?

5 What did you think of the (playgroup, childcare, family support) worker talking to you about your child's development?

6 Was it appropriate to discuss your child's development during (playgroup, childcare, family support)? Why do you say this?

7 What do you think CAFHN do?

8 What was it like seeing the CAFHN or the paediatric doctor at the (Centre name)?

9 What was it like seeing the paediatric doctor from the DAS (if appropriate)?

10 How do you think things would have gone if you had not seen the CAFHN and/or the paediatric doctor? Why do you say this?

11 What would you do now if you were worried about your child's development?

12 What would you like to see done differently? Why do you say this?

FIGURE 1: PARENT /GRANDPARENT FOCUS GROUP GUIDE

Telephone/face to face interviews: Participants were nominated by their organisations and invited to take part in an interview. Interviews were conducted by phone or face to face with NGO and health providers to understand the impact of the model on their work practices and the perceived impact on participating families using the interview guide in Figure 2. Interviews were recorded and transcribed. Interviews were conducted by KE. 


\section{Provider interview guide}

1 Can you please describe "Getting in Early - Getting it Right" to me?

2 Why do you think your service is part of "Getting in Early Getting it Right"?

3 How has taking part in "Getting in Early - Getting it Right" changed your relationship with the other services? Why do you say this?

4 How has "Getting in Early - Getting it Right" changed how you work?

5 What did you think of the training you received for "Getting in Early - Getting it Right"?

6 What sort of feedback do you get from referrals you make as a result of "Getting in Early - Getting it Right"?

7 What do you think has worked well so far in "Getting in Early Getting it Right"?

8 What do you think could work better in "Getting in Early Getting it Right"? Why do you say this?

9 What have families told you about what they think of "Getting in Early - Getting it Right"?

10 Would you remain engaged with the program if it continued? Why do you say this?

FIGURE 2: PROVIDER INTERVIEW GUIDE

Additional reports: Reports from a previous survey of parents in the Botany area, regarding barriers and enablers to accessing early childhood developmental surveillance were reviewed.

\section{DATA ANALYSIS}

Qualitative data was analysed by the research assistant (KE) using $\mathrm{NVivo}^{\mathrm{TM}} 1 \mathrm{O}$, against the expected outcomes of the projects and applying emergent themes approach within grounded theory. Analysis identified emerging themes related to processes and unintended consequences. Analysis continued until all major themes were identified.

Descriptive analyses of the quantitative data was undertaken by the project officer (LS) and project leads (TR; SW) in conjunction with the Centre for Research in Nursing and Health, University of Wollongong (RF), using the Statistical Package for the Social Sciences (SPSS ${ }^{\mathrm{TM}}$ version 24.0). Frequencies, means and their standard deviations were calculated for quantitative data. All quantitative activity data was de-identified. Pre and post training survey results used simple descriptive statistics to measure increase in knowledge, undertaken by the project officer (LS) and project leads (TR; SW).

\section{ETHICS}

Ethics approval was gained from the SESLHD Human Research Ethics Committee (HREC) ${ }^{1}$, with Site Specific Approval from Sydney Children's Hospital Network HREC². Information and consent forms for Nepali and Bengalispeaking participants were provided in English and in Nepali or Bengali. Translation was provided through the NAATI accredited SBS Translation Service.

\section{RESULTS}

\section{QUANTITATIVE DATA}

\section{Identification and referral}

Data for 149 children were analysed (Rockdale n=90*; Botany $\mathrm{n}=59^{* *}$ ) (Table 2 )

\section{TABLE 2: SAMPLE SIZE OF CHILDREN RECORDED (ROCKDALE AND BOTANY)}

\begin{tabular}{|l|l|l|}
\hline & Rockdale & Botany \\
\hline Male & 42 & 41 \\
\hline Female & 48 & 18 \\
\hline Age Range & Two months - 62 months & 12 months - 64 months \\
\hline $\begin{array}{l}\text { * Total families offered PEDS. } \\
\text { ** Children for whom PEDS referral was sent to SCHN (out of total } \\
\text { of 98 screened) by SECC and The Deli Women \& Children's Centre. } \\
\text { Data not available Botany Family \& Children Centre. }\end{array}$ \\
\hline
\end{tabular}

Of the 55 clients who saw the CAFHN, 43 were existing clients and 12 were new clients. Of the clients recorded as known to CAFHNs $(n=41), 63.4 \%(n=26)$ were not up to date with their scheduled child development checks. These checks are the means by which developmental issues can be identified early within a universal child health system, reducing the risk that delays in parental perception of developmental concern may delay identification and early intervention. The diagram below (Figure 3) describes the number of families offered PEDS, and those who accepted in the Rockdale project.

In Rockdale, $45 \%$ of children lived in a home where English was not the language spoken at home. After English, Nepali was the most frequently spoken language at home, followed by Mandarin and Cantonese. A record was kept of the number and proportion of parents requiring an interpreter for their initial and ongoing contact with Child and Family Health Services. Of the 88 parents recorded for this characteristic, $5.7 \%(n=5)$ required an interpreter. 


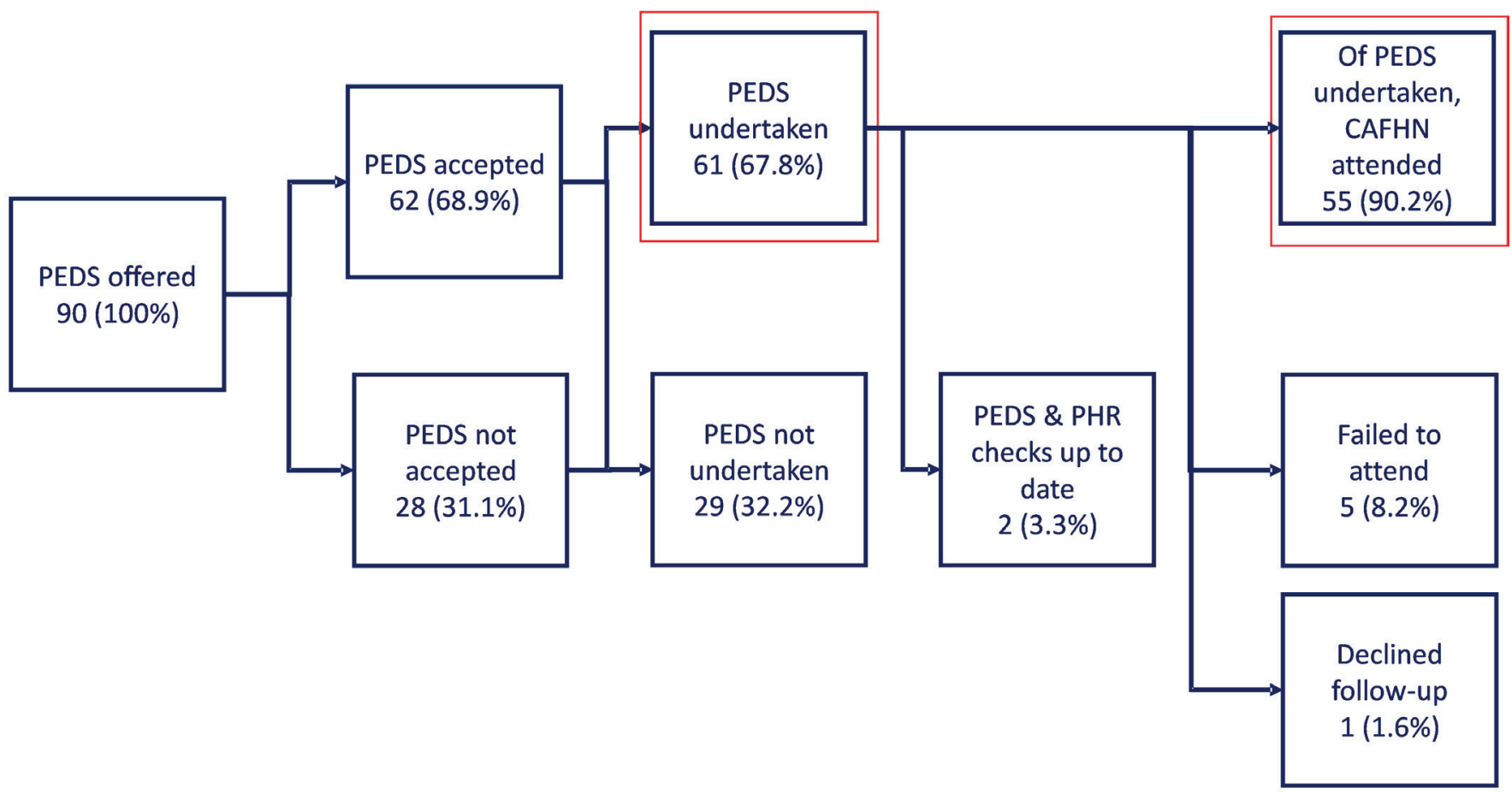

FIGURE 3: ROCKDALE NUMBERS UNDERTAKING PEDS AND REFERRED TO CAFHN

Note: This data was available for Rockdale only and not for the Botany arm.

TABLE 3: CHILDREN IDENTIFIED WITH ONE OR MORE PREDICTIVE CONCERN BY LANGUAGE (ENGLISH/NON-ENGLISH) SPOKEN AT HOME (ROCKDALE)

\begin{tabular}{|l|r|r|r|r|r|}
\hline $\begin{array}{l}\text { PEDS Outcome } \\
\text { Pathways }\end{array}$ & \multicolumn{2}{|c|}{ English } & \multicolumn{2}{|c|}{$\begin{array}{c}\text { Other } \\
\text { than English }\end{array}$} & Total \\
\cline { 2 - 5 } & $\mathrm{n}$ & $\%$ & $\mathrm{n}$ & $\%$ & \\
\hline $\begin{array}{l}\text { A - two or more } \\
\text { predictive concerns }\end{array}$ & 7 & $58 \%$ & 5 & $42 \%$ & 12 \\
\hline $\begin{array}{l}\text { B - one predictive } \\
\text { concern }\end{array}$ & 5 & $46 \%$ & 6 & $54 \%$ & 11 \\
\hline & 12 & $52.2 \%$ & 11 & $8.7 \%$ & 23 \\
\hline
\end{tabular}

\section{PREDICTIVE CONCERNS} (ROCKDALE AND BOTANY)

Of the 61 Rockdale families and 98 Botany families who undertook the PEDS, $37.7 \%$ and $40.6 \%$ were recorded with one or more predictive concerns on the PEDS, indicating developmental vulnerability and requiring further assessment and referral.

The Rockdale project recorded the number of children with predictive concerns identified by the CAFHN, by home language, and the results are shown below for the top language groups.
TABLE 4: NUMBERS OF CHILDREN PREVIOUSLY KNOWN TO THE CAFHN, WHO RECONNECTED AND WERE IDENTIFIED AS HAVING ONE OR MORE PREDICTIVE CONCERNS (ROCKDALE)

\begin{tabular}{|l|r|r|}
\hline PEDS Outcome Pathways & $\begin{array}{r}\text { PHR child } \\
\text { development } \\
\text { check NOT up } \\
\text { to date }\end{array}$ & $\begin{array}{r}\text { PHR child } \\
\text { development } \\
\text { check up to } \\
\text { date }\end{array}$ \\
\hline $\begin{array}{l}\text { A - two or more predictive } \\
\text { concerns }\end{array}$ & 9 & 1 \\
\hline B-one predictive concern & 2 & 3 \\
\hline
\end{tabular}

Children identified as having two or more predictive concerns were more likely to be not up to date with their PHR child development check. Of 10 children identified as having two or more predictive concerns, who were previously known to the CAFHN and had reconnected with the service, nine were not up to date with the PHR child development checks (see below).

\section{DEVELOPMENTAL AREAS OF CONCERN (ROCKDALE AND BOTANY)}

Figure 4 describes the developmental areas of concern identified in assessments. The highest proportion of identified concerns was in expressive language and articulation and in behaviour. 
Percentage of children identified with developmental areas of concern

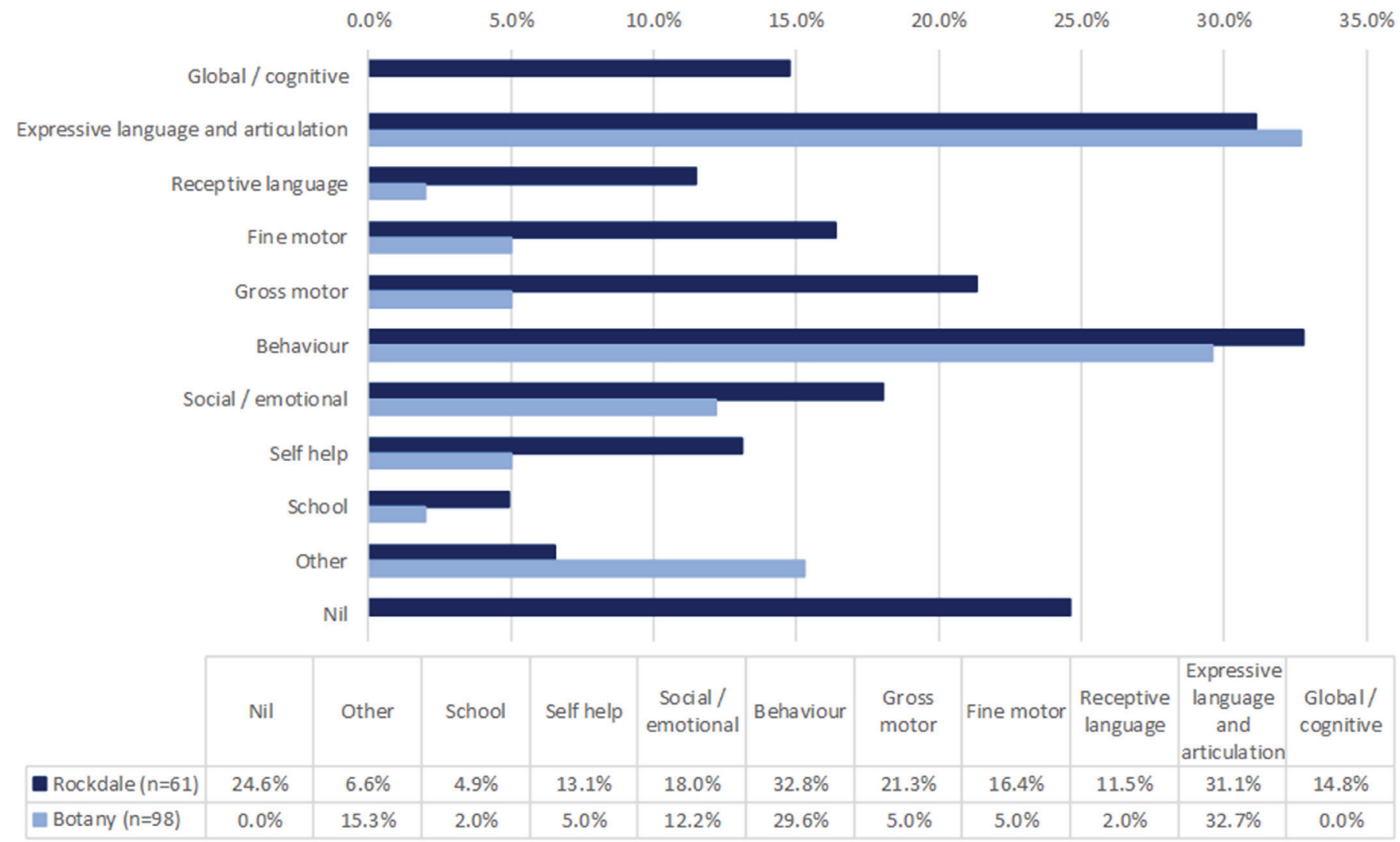

FIGURE 4: IDENTIFIED DEVELOPMENTAL AREA OF CONCERN (ROCKDALE AND BOTANY)

Referrals made by CAFN/Community Child Health for further assessment

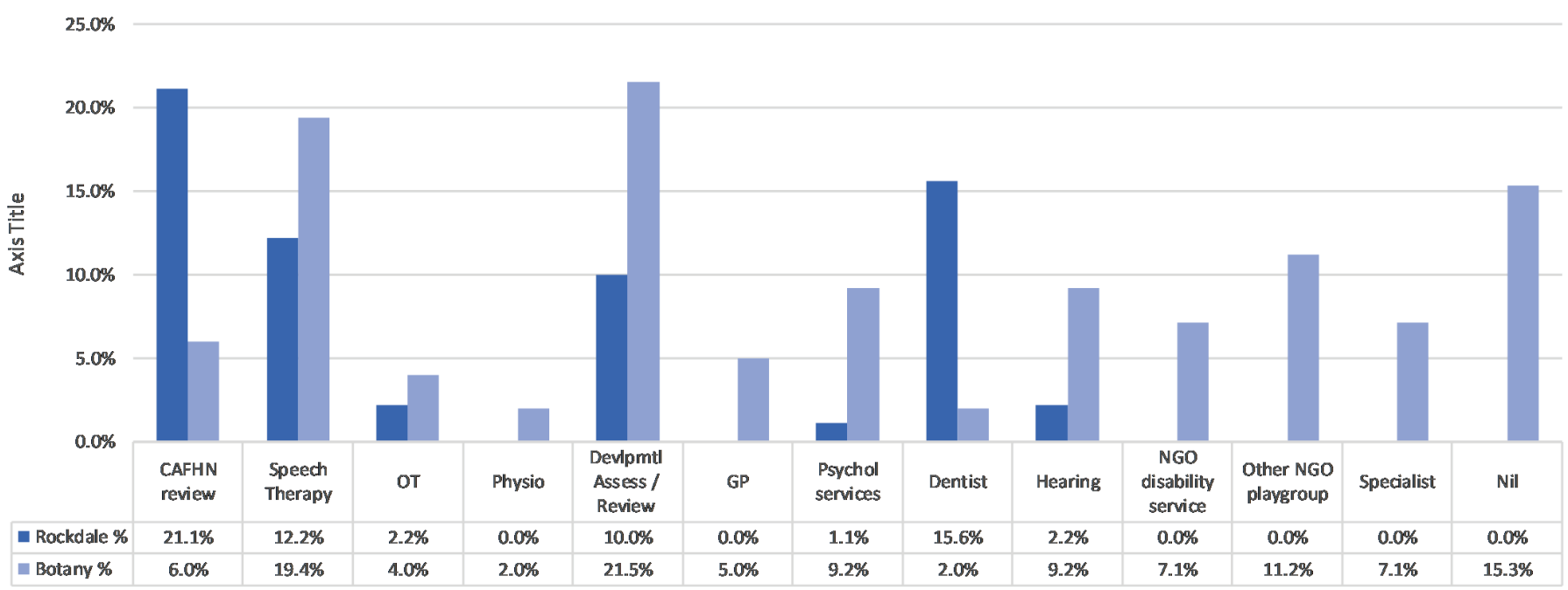

FIGURE 5: REFERRALS MADE BY CAFHN/COMMUNITY CHILD HEALTH FOR FURTHER ASSESSMENT (ROCKDALE AND BOTANY) 


\section{REFERRALS FOR FURTHER ASSESSMENT (ROCKDALE AND BOTANY)}

Referrals were made to a range of child and family services as a result of initial assessment. Figure 5 (below) shows the variation in referrals across the two projects. Both projects had similar rates of referral to Developmental Assessment Services.

More families were referred to speech pathology services from Botany, where a speech pathologist was a member of the project team. A higher proportion of children in Botany were referred for developmental assessment/review, which may reflect the team being led by community paediatricians and community child health doctor in the early stages.

A higher proportion of Rockdale families were referred to dental services, driven by CAFHNs including "Lift the Lip" (oral health check) in their child development check and the health service dental service providing an on-site screening visit.

\section{QUALITATIVE DATA}

\section{IMPROVED KNOWLEDGE AND REFERRALS BY NGO PROVIDERS}

In questionnaires administered pre and post-training, nonhealth staff who attended the training reported a gain in knowledge and/or confidence relating to early childhood development and surveillance from $68.4 \%$ to $71.4 \%$.

In interview, Developmental Assessment Services (DAS) reported a change in the level of need in referrals they were receiving, as well as a perceived increase in the range of families from CALD backgrounds being referred for further assessment.

\section{INCREASED FAMILY COMFORT WITH AND ACCESS TO CAFHN}

Focus groups with families in Rockdale and Botany revealed that few of the participants distinguished between the services provided by the on-site CAFHN and accessed through the supported playgroup, and the activities provided in the supported playgroup itself. This was particularly noticeable in the English-speaking focus group where questions regarding CAFHNs were answered in terms of the parents' overall experience with the supported playgroup that they attended.

“... all of us different cultures, different kind of things here, so we don't know what to do. So at least if we have professional help, it will make - leave us in peace."

Parent from English-speaking group

Where parents in focus groups differentiated between services provided by the playgroup and those provided by the CAFHN, they described the support they received from CAFHNs as including advice about eating and sleeping, establishing routines, dental care and tips for playing with children.
"It was good. It was good. She's the one who told me that just, like, she said, she's the one who told me that I need to brush his teeth, because I thought, we should have started brushing his teeth at around two or something, because I just usually use my hand, but then, now we starting to brush his teeth..." Parent from English-speaking group

"Child and Family Health Nurses give tips during consultations; give us helpful tips and guide us in case we are ignorant about certain things and so on. Therefore, it is good to discuss with Child and Family Health Nurses as we get guidance from them to teach our children as they are experienced and have qualifications."

Parent/Grandparent from Nepali-speaking group

The regular contact with early childhood health professionals was viewed by health service early childhood health professionals, participating CAFHNs, and NGO services as a strong enabler in encouraging parents to follow up referrals and remain engaged.

“...it has been really good to be able to say this is a person you might need for your process of assessment. So... really having that soft entry point has been most helpful."

Botany Early Childhood Service Provider

\section{A TEAM-BASED APPROACH}

Several participants from NGO services emphasised the importance of supporting families to follow through on referrals and attend assessments. They saw the projects as a team effort, with each agency involved providing a specific element of the overall project. In both Botany and Rockdale, interviewees commented on the value they gained from the ongoing relationship with child and family health services and CAFHNs. They reported increased confidence that their opinions were respected and families seen in a timely manner. Similarly, health professionals, including CAFHNs, commented on the importance of engaging with NGO early childhood/ family support services and building good relationships.

"I think it's the personal contact, I think it's knowing the people. Them knowing us and us knowing them, I really think that makes a big difference that people know who you are." SESLHD Health Professional

\section{DISCUSSION}

This is the first study to examine models of care which specifically address access for culturally diverse and socioeconomically disadvantaged communities to early childhood developmental surveillance and CAFHNs by partnering with community organisations. Consistent with the emerging evidence on these models we found that these outreach models are more effective in engaging families of low socioeconomic background in participating in developmental screening, with earlier detection of neurodevelopmental vulnerabilities. ${ }^{10,11}$ 
A key component contributing to the model's success is training of non-government organisation staff in early childhood development. Understanding developmental risk and the steps that can be taken to address this has helped staff in the participating NGO services to identify children who will benefit from further screening, and to more effectively use the existing universal developmental surveillance provided through early childhood health services. Although NGO staff generally reported a good baseline knowledge of child development prior to training, their reported confidence in being able to apply this knowledge when talking with families about early childhood development and concerns improved following the training.

A similar result was found in Victoria, Australia, where The Wodonga Early Years' Service Coordination Framework tested the PEDS with childcare workers, pre-school teachers and primary school teachers, as well as child and maternal health services. The PEDS was reportedly easy to use across these different service providers and was also well-received by parents. There was increased capacity for early childhood service/education providers and child and maternal health services to appropriately refer. ${ }^{10}$

In terms of the significance for nursing, this study has demonstrated the utility of a model of developmental surveillance and entry into the child and family health system in a non-health setting.

Co-location of a CAFHN on-site at the Rockdale NGO service was recognised as an enabling factor in parents attending initial assessments and further developmental assessments if required. CAFHNs noted the ability to observe children and families in the supported playgroup as of added value in the assessment process.

In this study, by having regular contact with a CAFHN in a safe, supportive and familiar environment, families who might otherwise not attend child and family health clinics were introduced to CAFHNs, developmental surveillance activities and provided with ongoing support if developmental vulnerabilities were identified.

Consistent with previous literature we demonstrated that those children who are most likely to be developmentally vulnerable were the least likely to have had developmental surveillance done in their health checks., ${ }^{5,12}$ In our study, we also found that children identified with one or more predictive concerns were less likely to be up to date with their child health checks. In other words, our new model of care has found children who might not have been identified as having a developmental concern until they were attending primary school, and ensured that they are linked into essential early intervention.

\section{CONCLUSION}

The Botany and Rockdale models of care have demonstrated the potential for improving access to CAFHNs and other early childhood developmental health services, developmental surveillance, detection of developmental concerns and early intervention for children from culturally and linguistically diverse backgrounds. We have shown that child health services and CAFHN services can change their practice, can successfully provide developmental surveillance in locations apart from child and family health centres, and can work in collaboration with the NGO sector. Our next steps are to scale up these models across multiple sites and with different priority populations.

\section{Acknowledgements}

The authors would like to thank the parents and grandparents who generously shared their time and experiences with the project. We would also like to acknowledge the CAFHNs who worked on this project and embraced a new model of working with their vulnerable clients and the non-government services who willingly adapted their services and venues to accommodate these models of care.

\section{Conflict of interest}

K Edwards was contracted to undertake the independent evaluation of the project, on which this article is based.

\section{Funding}

This project was funded by two grants:

1) 20172018 Sydney Children's Hospital Foundation - Early Childhood Development - Getting it Right, Getting in Early

2) 20172018 NH\&MRC Advanced Health Research and Translation Centre, SPHERE Improving access to developmental surveillance, Early Life Determinants of Health (ELDoH): Invest Early To Make a Difference

\section{Author contributions}

SW TR DP RS and LS contributed to the design of the study. RF, KE, TR and SW undertook the analysis. All authors contributed to the writing of this article. Primary author was KE and senior author SW.

\section{REFERENCES}

1 Goldfeld S, O'Connor M, Sayers M, Moore T, Oberklaid F. Prevalence and correlates of special health care needs in a population cohort of Australian children at school entry. J Dev Behav Pediatr. 2012; 33: 319-327.

2 Guralnick $M$. Effectiveness of early intervention for vulnerable children: a developmental perspective. Am J Ment Retard. 1997; 102(4):319-345

3 Goldfeld S, O'Connor M, Mithen J, Sayers M, Brinkman S. Early development of emerging and english-proficient bilingual children at school entry in an Australian population cohort. Int JBehav. 2014; 38(1): 42-51. 
4 Woolfenden S, Posada N, Krchnakova R, Crawford J, Gilbert J, Jursik B, et al. Equitable access to developmental surveillance and early intervention--understanding the barriers for children from culturally and linguistically diverse (CALD) backgrounds. Health Expect. 2015; 18(6):3286-3301.

5 Garg PG, Ha MT, Eastwood J, Harvey S, Woolfenden S, Murphy $\mathrm{E}$, et al. Explaining Culturally and Linguistically Diverse (CALD) parents' access of healthcare services for developmental surveillance and anticipatory guidance: qualitative findings from the 'Watch Me Grow' study. BMC Health Serv. 2017; 17:228.

6 King TM, Tandon SD, Macias MM, Healy JA, Duncan PM, Swigonski NL, et al. Implementing developmental screening and referrals: lessons learned from a national project. Pediatrics. 2010; 125(2):350-60.

7 Riggs E, Davis E, Gibbs L, Block K, Szwarc J, Casey S, et al. Accessing maternal and child health services in Melbourne, Australia: reflections from refugee families and service providers. BMC Health Serv. 2012; 12(1):117.

8 Ennis-Cole D, Durodoye BA, Harris HL. The impact of culture on autism diagnosis and treatment: considerations for counselors and other professionals. Fam J. 2013; 21(3):279-87.

9 Lynam MJ, Loock C, Scott L, Wong SM, Munroe V, Palmer B. Social paediatrics: creating organisational processes and practices to foster health care access for children 'at Risk'. J Res Nurs. 2010; 15(4):331-47.

10 Armstrong MF, Goldfeld S. Systems of early detection in Australian communities: the use of a developmental concern questionnaire to link services. Aust J Adv Nurs. 2008; 25(3):7.

11 Rybski DA, Wilder E. A pilot study to identify developmental delay in children in underserved urban community child care settings. J of Allied Health. 2008; 37(1):e34-49.

12 Woolfenden S, Eapen V, Jalaludin B, Hayen A, Kemp L, Dissanyake $C$, et al. Prevalence and factors associated with parental concerns about development detected by the Parents' Evaluation of Developmental Status (PEDS) at 6-month, 12-month and 18-month well-child checks in a birth cohort. BMJ open. 2016; 6(9):e012144. 